\title{
Morphogenetic response of shoot tips to cryopreservation by encapsulation-dehydration in a solid mutant and periclinal chimeras of Chrysanthemum $\times$ grandiflorum /Ramat./Kitam.
}

\author{
Dariusz Kulus $^{1} \cdot$ Agnieszka Abratowska² $^{2}$ Anna Mikuła ${ }^{3}$
}

Received: 24 May 2017 / Revised: 9 October 2017 / Accepted: 14 December 2017 / Published online: 22 December 2017

(c) The Author(s) 2017. This article is an open access publication

\begin{abstract}
Cryopreservation is widely applied to many economically important species excluding chimera plants which are problematic for long-term conservation. Their storage problems can be circumvented only by cryopreserving meristems. This study looked at the morphogenetic response of shoot tips of periclinal chimera chrysanthemum 'Lady Orange' and 'Lady Salmon', as well as the solid mutant 'Richmond', that were cryopreserved by encapsulation-dehydration technique. By applying $10 \mu \mathrm{M} \mathrm{ABA}$ in the preculture medium followed by 4-day-long dehydration treatment, the explant survival reached up to $67 \%$. Besides the stimulation of typical single shoot recovery, cryopreservation led to direct or indirect multiple shoot formation, shoot malformation, as well as inhibited their spontaneous rooting. Microscopic analysis revealed three types of structural damages of shoot tips which can correspond with their morphogenetic response in recovery culture. No influence of cryostorage on the acclimatisation efficiency of the recovered chrysanthemums was observed.
\end{abstract}

Keywords Acclimatisation $\cdot$ Callus $\cdot$ Morphogenesis $\cdot$ Multiplication $\cdot$ Rooting $\cdot$ TEM

\section{Introduction}

Plants which have one layer of cells that is genetically distinct from another layer are very popular among ornamental plant species such as Pelargonium spp., Chrysanthemum $\times$ grandiflorum /Ramat./Kitam., Taxus baccata L., +Laburnocytisus 'Adamii', Ficus benjamina L., Scindapsus pictus Hassk., Saintpaulia ionantha H.Wendl. Since the nineteenth century, they are used in horticultural production as a source of new phenotypes (Stewart et al. 1972;

Communicated by M. Lambardi.

Dariusz Kulus

dkulus@gmail.com

1 Faculty of Agriculture and Biotechnology, UTP University of Science and Technology, Poland, Bernardyńska 6, 85-029 Bydgoszcz, Poland

2 Laboratory of Ecotoxicology, Faculty of Biology, Institute of Botany, University of Warsaw, Miecznikowa 1, 02-096 Warsaw, Poland

3 Centre for Biological Diversity Conservation in Powsin, Polish Academy of Sciences Botanical Garden, Prawdziwka 2, 02-973 Warsaw, Poland
Zonneveld 2007). Moreover, chimeras are also useful in evaluating the interactions between cells during plant development (Szymkowiak and Sussex 1996; Yamaguchi et al. 2009). However, these plants are problematic in propagation and storage. Rearrangement of histogen layers by the L1 cell damage or their replacement by the ones from the L2 layer results in the change in colour and/or shape of flowers or more rarely in leaves (Bush et al. 1976; Zonneveld and Van Iren 2000). Therefore, for the purpose of reproduction and conservation only vegetative propagation methods based on exploitation of meristematic tissues can be applied. In order to achieve those goals, in vitro tissue-based cultures (Kereša et al. 2012) and cryopreservation (Fukai et al. 1994) are becoming more and more popular.

The potential of low temperatures in storage of genetic resources is well known (Engelmann 2011). The past few decades have witnessed a tremendous progress in the development and application of cryopreservation techniques to conservation of numerous ornamental plants (Kulus and Zalewska 2014a). Several cryopreservation techniques have also been already established with chrysanthemum, in which cell dehydration is performed by two methods: osmotical (usually by applying media or solutions with increased sucrose content) or physical, i.e., under silica gel or sterile air flow (Teixeira da Silva 
and Kulus 2013; Kulus 2015). Each cryopreservation step (preculture, pretreatment, freezing/rewarming and recovery) may influence the viability and morphogenetic response of the cells, as observed by Martín et al. (2011) with chrysanthemum 'Pasodoble'. The influence of preculture and various cryotreatment on the morphogenetic potential of shoot tips cryopreserved in liquid nitrogen (LN) is still not fully understood, in particular, in the field of chimeras.

One of the methods, which can be applied in the screening of cryopreserved explant survival and integrity, is their microscopic observation. Electron microscopy is a very useful tool used in cryobiology, which enables tracking how soon after rewarming do the thawed tissue regain its original state of vacuolisation, or the explant regeneration path. Histological and ultrastructural (transmission electron microscopy, TEM) analyses of Dianthus shoot tips (Kartha 1985), Hypericum perforatum L. tissues (Skyba et al. 2012), as well as Dendrobium sonia-28 (Poobathy et al. 2013) and Oncidium hamana 'Elfin' (Miao et al. 2005) protocorm-like bodies (PLBs) were used in order to indicate to which explant regions do the freezing and thawing cycles inflict most damages. Cellular and subcellular changes after various cryopreservation regimes were examined to explain the mechanism of the beneficial effect of different pretreatment conditions (Miao et al. 2005; Mikuła et al. 2005; Kushnarenko et al. 2010). Structural modifications in the mesophyll and chloroplasts associated with cryopreservation of seven Hypericum species were performed by StoyanovaKoleva et al. $(2013,2015)$. Ultrastructural observations were carried out on radicles and shoot tips of embryonic axes of Acer saccharinum L. to assess immediate (i.e., pre-thaw) responses to cooling treatments (Wesley-Smith et al. 2014). Only few works have focussed on the effect of cryopreservation on the structure of shoot apex area (Fukai and Oe 1990; Helliot et al. 2003; Wilkinson et al. 2003). Using light and electron microscopy, the tunica and corpus cell tolerance to ultra-low temperatures in tomato was recently shown (Halmagyi et al. 2017). It is worth emphasising that no attention has been paid to the ultrastructural changes associated with various morphogenetic responses of cryopreserved explants. This aspect is especially important with periclinal chimeras, which require full survival of the tunica layers in order to maintain their stability.

The aim of this study was to evaluate the influence of cryopreservation on the morphogenetic response of shoot tip explants in chrysanthemum chimeras.

\section{Materials and methods}

\section{Plant material}

Chrysanthemum (Chrysanthemum $\times$ grandiflorum /Ramat./ Kitam.) 'Richmond', 'Lady Orange' and 'Lady Salmon' obtained via radiomutation (Zalewska et al. 2007) were the source of plant material. Purple-flowering 'Richmond' is a stable cultivar in terms of flower colour while 'Lady Orange' and 'Lady Salmon' are periclinal chimeras (Zalewska et al. 2007).

Plantlets were maintained on the modified MS medium (Murashige and Skoog 1962) with an increased by half concentration of calcium chloride and iron sulphate. The medium was supplemented with $0.09 \mathrm{M}$ sucrose and solidified with $0.8 \%$ agar; $\mathrm{pH} 5.8$ was determined before autoclaving. Shoot cultures were kept in glass jars of $350 \mathrm{ml}$ volume (six shoots per jar), in the growth room under $16 / 8 \mathrm{~h}$ photoperiod conditions and photosynthetic photon flux density of $27.4 \mu \mathrm{mol} \mathrm{m}{ }^{-2} \mathrm{~s}^{-1}$, at $24 \pm 2{ }^{\circ} \mathrm{C}$.

\section{Cryopreservation procedure}

\section{Preculture}

The single-node explants of chrysanthemum, without leaves, were precultured for 7 days on the MS medium (as already described) in the presence of $0.09 \mathrm{M}$ sucrose. Then, the explants were subcultured to the same medium, but additionally supplemented with $10 \mu \mathrm{M}$ of abscisic acid (ABA) for the next week. Ten explants were inoculated in a single jar. The shoot tips isolated from axillary shoots were used for the further experiments.

\section{Encapsulation/dehydration procedure}

The shoot tips (approximately $2.0 \mathrm{~mm}$ in length) with two leaf primordia and very young leaf were incubated in 3\% sodium alginate (10 min) based on the modified MS medium salts, without $\mathrm{CaCl}_{2}$, supplemented with $0.09 \mathrm{M}$ sucrose and then dipped into $0.1 \mathrm{M} \mathrm{CaCl}_{2}$ for $30 \mathrm{~min}$, forming calibrated beads (3-4 $\mathrm{mm}$ in diameter). The beads were washed with bidistilled sterile water and osmotically dehydrated in liquid MS medium, with gradually raised level of sucrose concentrations, as follows: $0.30 \mathrm{M}(24 \mathrm{~h})$ then in $0.50 \mathrm{M}(24 \mathrm{~h})$ then in $0.75(24 \mathrm{~h})$ and, finally, in $1.0 \mathrm{M}(24 \mathrm{~h})$. The beads were maintained in agitation in the liquid medium using "Infors" shaker with $130 \mathrm{rpm}$ (4.5 amplitude), in darkness. Then, the beads were air-desiccated for $3 \mathrm{~h}$ ( $40 \%$ of the initial fresh weight), loaded into $2.0 \mathrm{ml}$ cryovials (20 beads per tube) and immersed directly into $\mathrm{LN}\left(-196^{\circ} \mathrm{C}\right)$ for at least $1 \mathrm{~h}$.

The plant material was rewarmed in a water bath at $38 \pm 1{ }^{\circ} \mathrm{C}$ for $3 \mathrm{~min}$, and the encapsulated shoot tips were transferred on the modified MS recovery medium supplemented with $0.09 \mathrm{M}$ sucrose and $1.16 \mu \mathrm{M}$ kinetin (KIN) (10 beads per $90 \mathrm{~mm}$ Petri dish). The explants were cultured in darkness for 2 days. Next, the beads were transferred to a 16/8 day/night photoperiod and kept at a light intensity of $12.2 \mu \mathrm{mol} \mathrm{m} \mathrm{m}^{-2} \mathrm{~s}^{-1}$ for a further 5 days. 


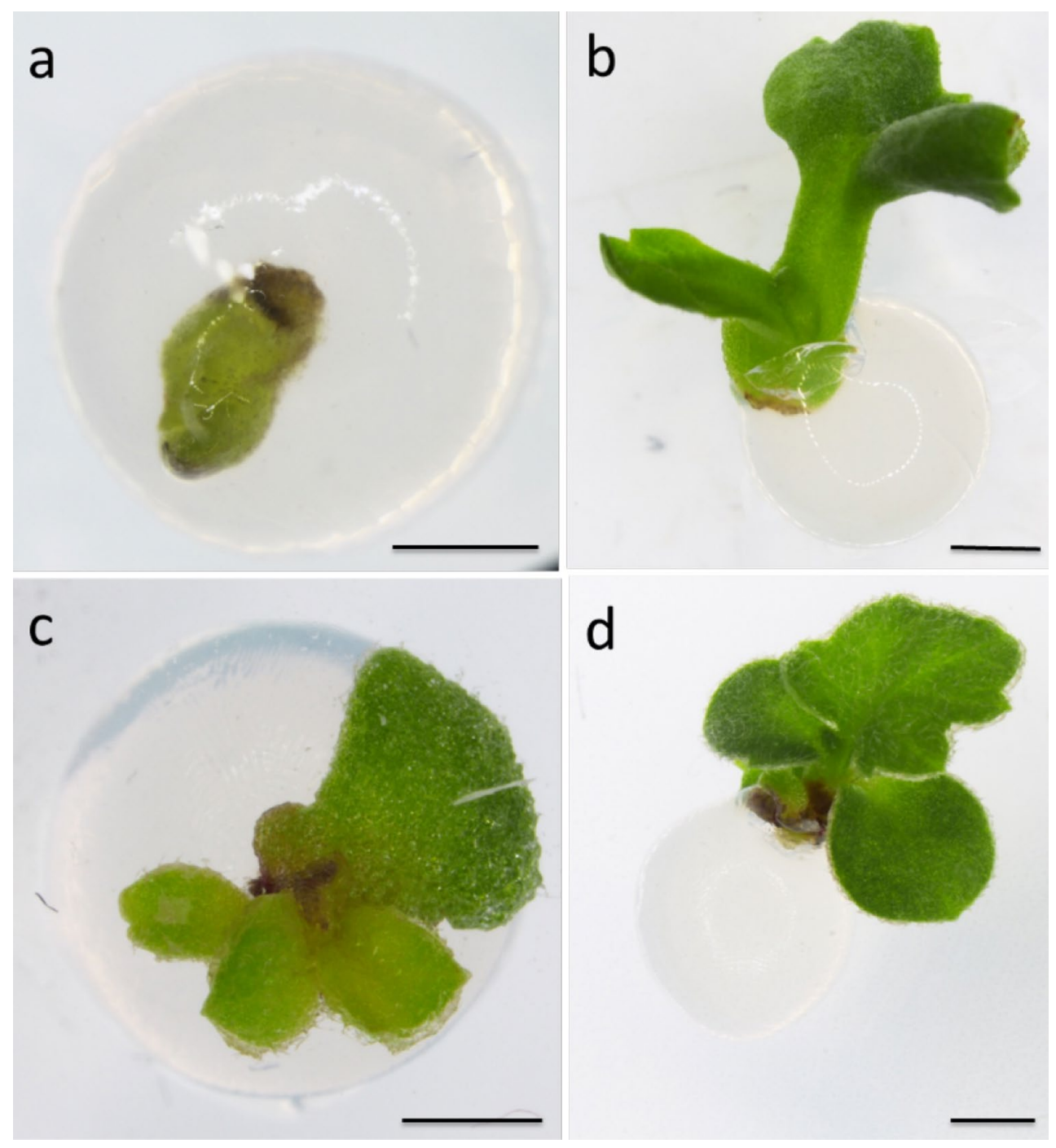

Fig. 1 'Richmond' shoot tip development after cryopreservation. a

oping inside the bead (22 days after rewarming) or $\mathbf{d}$ on its surface Shoot tip directly after rewarming; b first developing leaf breaking the bead (15 days after rewarming); $\mathbf{c}$ shoot with several leaves devel-

\section{Table 1 Effect of}

cryopreservation $(\mathrm{LN})$ on the shoot tip survival 7 days after rewarming, and the method of shoot formation and their spontaneous rooting after 60 days of post-thaw culture

\begin{tabular}{|c|c|c|c|c|c|c|c|c|c|c|}
\hline & \multirow{2}{*}{\multicolumn{2}{|c|}{ Survival [\%] }} & \multicolumn{6}{|c|}{ Shoot formation [\%] } & \multirow{2}{*}{\multicolumn{2}{|c|}{$\begin{array}{l}\text { Spontaneous } \\
\text { rooting [\%] }\end{array}$}} \\
\hline & & & \multicolumn{2}{|c|}{ Single, direct } & \multicolumn{2}{|c|}{ Multiple, direct } & \multicolumn{2}{|c|}{$\begin{array}{l}\text { Multiple, } \\
\text { indirect }\end{array}$} & & \\
\hline & Control & $\mathrm{LN}$ & Control & $\mathrm{LN}$ & Control & LN & Control & $\mathrm{LN}$ & Control & $\mathrm{LN}$ \\
\hline 'Lady Orange' & $100 a^{*}$ & $42.5 \mathrm{c}$ & $100 \mathrm{a}$ & $65.2 \mathrm{c}$ & $0.0 \mathrm{a}$ & $28.5 \mathrm{ab}$ & $0.0 \mathrm{a}$ & $6.3 \mathrm{~b}$ & $100 * \mathrm{a}$ & $65.2 \mathrm{~b}$ \\
\hline 'Lady Salmon' & $100 \mathrm{a}$ & $53.1 \mathrm{bc}$ & $100 \mathrm{a}$ & $48.2 \mathrm{~d}$ & $0.0 \mathrm{a}$ & $41.5 \mathrm{~b}$ & $0.0 \mathrm{a}$ & $10.3 \mathrm{~b}$ & $100 \mathrm{a}$ & $41.5 \mathrm{c}$ \\
\hline 'Richmond' & $100 \mathrm{a}$ & $66.7 \mathrm{~b}$ & $100 \mathrm{a}$ & $80.6 \mathrm{~b}$ & $0.0 \mathrm{a}$ & $15.7 \mathrm{a}$ & $0.0 \mathrm{a}$ & $3.7 \mathrm{~b}$ & $100 \mathrm{a}$ & $75.0 \mathrm{~b}$ \\
\hline
\end{tabular}

Control refers to shoots recovered from non-precultured and non-cryotreated shoot tips. Single and multiple refer to the number of shoots recovered from a single shoot tip; direct and indirect refer to the morphogenetic response of explants

*Means marked with the same letter do not differ significantly at $P=0.05$ 
Afterwards, the cultures were transferred to initial lighting conditions. After 1 month of culture, the beads were subcultured to a MS medium without plant growth regulators (MS0) for plantlet elongation.

\section{Viability assessment}

The cryopreservation effectiveness was evaluated by the explant survival, 7 days after rewarming. The total number of cryopreserved shoot tips was considered $100 \%$. Furthermore, the percentage of the explants forming single and multiple shoots (i.e., which formed in the number of at least two from a single shoot tip directly or indirectly) was evaluated after 60 days. Spontaneously, adventitious root formation was determined 60 days after rewarming. The results were referred to control explants and shoots (i.e., recovered from non-precultured and non-cryotreated shoot tips).

\section{Microscopic analysis}

Plant material samples consisted of 'Lady Orange' and 'Lady Salmon' shoot tips (containing two leaf primordia and one young leaf) were harvested 2 and 5 days after rewarming. Untreated explants were used as a control. A number of 20 shoot tips from each of the six combinations were prepared for light and transmission electron microscopy studies. The extent and severity of injuries after rewarming were assessed in all layers of meristem and leaf-primordium cells.

The biological material was fixed in $2.5 \%$ glutaraldehyde in $0.1 \mathrm{M}$ cacodylate buffer with $1 \%$ caffeine ( $\mathrm{pH}$ 7.2) for $2 \mathrm{~h}$. Next, the shoot tips were rinsed three times with cacodylate buffer with caffeine for a total $30 \mathrm{~min}$, followed by post-fixation with $2 \%$ osmium tetroxide $\left(\mathrm{OsO}_{4}\right)$ overnight at $4{ }^{\circ} \mathrm{C}$. Then samples were dehydrated in a graded series of ethanol and propylene oxide, and gradually embedded in a mixture of Epon and Spurr resins (Hunter 1993). The samples were polymerised at $58{ }^{\circ} \mathrm{C}$ for $72 \mathrm{~h}$. Semi-thin $(2 \mu \mathrm{m})$ and ultra-thin $(80 \mathrm{~nm})$ sections were cut with an TESLA BS 490A and Diatome PowerTome XL RMC ultramicrotomes on glass knife and diamond knife (Drukker), respectively. Semi-thin sections were stained with $0.5 \%$ toluidine blue (TB) in $1 \%$ borax (10 s) and analysed with a Vanox-Olympus light microscope. Ultrathin sections were contrasted with uranyl acetate for $30 \mathrm{~min}$. After washing the samples were transferred to a Reynold solution (lead citrate) (Reynolds 1963) for $30 \mathrm{~min}$, and then observed in a transmission electron microscope ZEISS Libra 120 (acceleration $120 \mathrm{kV}$ ). Photographic documentation was performed with the use of Olympus iTEM 5.1 software.

\section{Rooting and acclimatisation}

Six months after thawing of shoot tips, plantlets were rooted and acclimatised, i.e., 32-'Richmond', 36-'Lady Orange', 22-'Lady Salmon' and additional 10-15 controls from each cultivar.

For rooting, the 3-cm-long distal shoot fragments were dissected and transferred on the rooting MS medium containing half-strength macronutrients ( $1 / 2 \mathrm{MS})$ and supplemented with $11.42 \mu \mathrm{M}$ of 3 -indoleacetic acid (IAA) for 10 days.

Acclimatisation was conducted for 21 days in January in natural light conditions in a glasshouse at the temperature $18-21{ }^{\circ} \mathrm{C}$. Chrysanthemums were grown in plastic trays (36 plants per tray) filled with a mixture of peat and perlite (2:1; disinfected with $0.2 \% \mathrm{v} / \mathrm{w}$ Dithane), sprayed for 1 week, and covered with perforated foil and geo-cover. The effectiveness of rooting and acclimatisation was assessed.
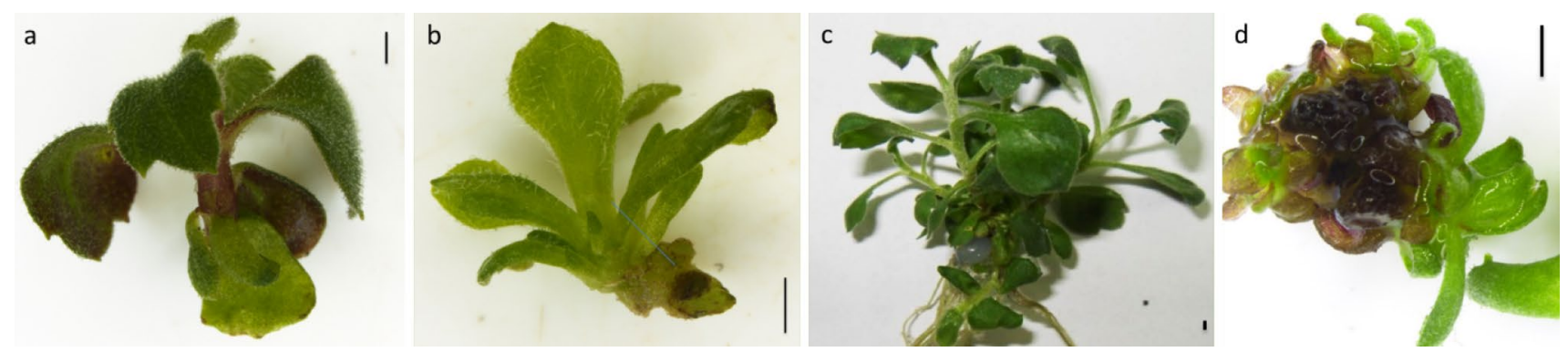

Fig. 2 Morphogenetic reactions of the chrysanthemum 'Lady Orange' shoot tips during recovery culture. a A single shoot recovered from control shoot tip after 30 days of culture, $\mathbf{b}$ a single shoot developed after cryopreservation, 30 days after rewarming, $\mathbf{c}$ multi- ple shoots developed after cryopreservation; 60 days after rewarming, d adventitious shoot regeneration; 60 days after rewarming $($ bar $=1 \mathrm{~mm})$ 


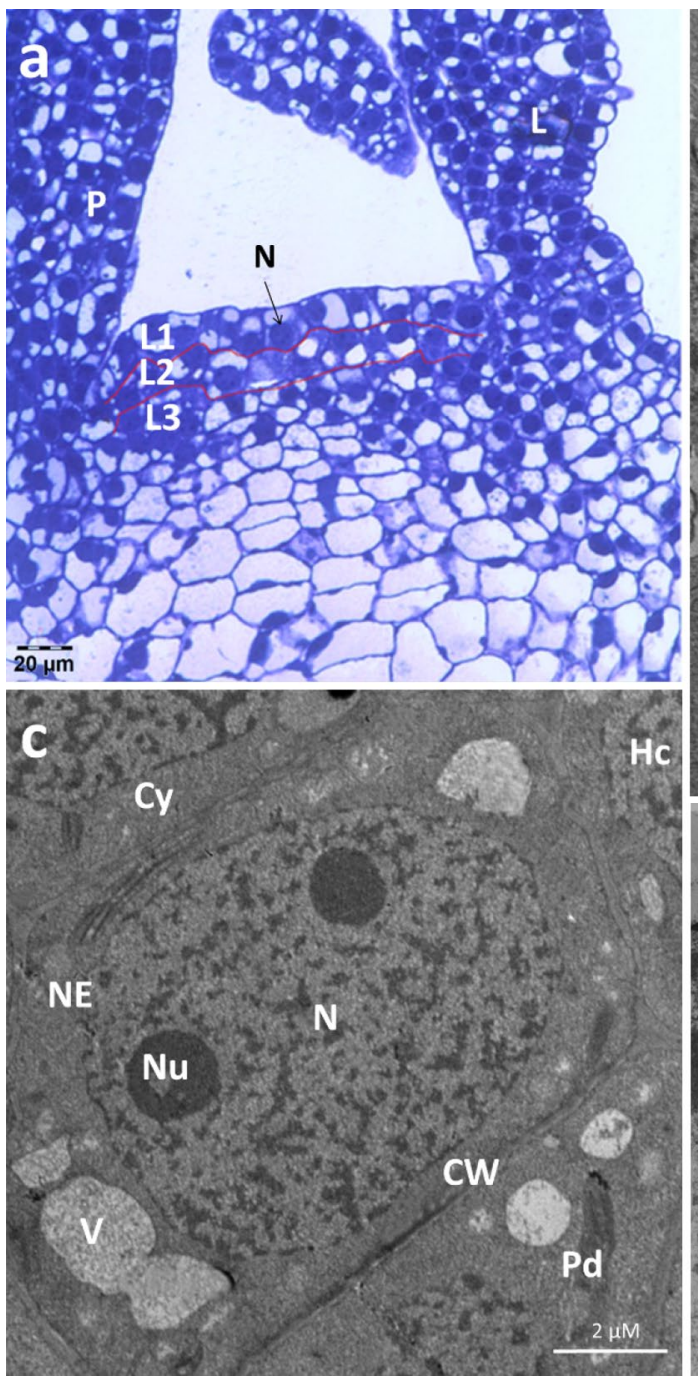

Fig. 3 Longitudinal section through a control shoot tip of 'Lady Orange'. a An overall photograph of a control shoot apical meristem with separate histogen layers (semi-thin section, TB-stained). b L1 layer active cell with numerous mitochondria and plastids filled with starch, covered with cuticle, $\mathbf{c}$ typical L2 layer cell with two nucleoli in a single nucleus with an intact smooth nuclear envelope, a plastid and numerous vacuoles, $\mathbf{d}$ corpus cells: cellular overview showing

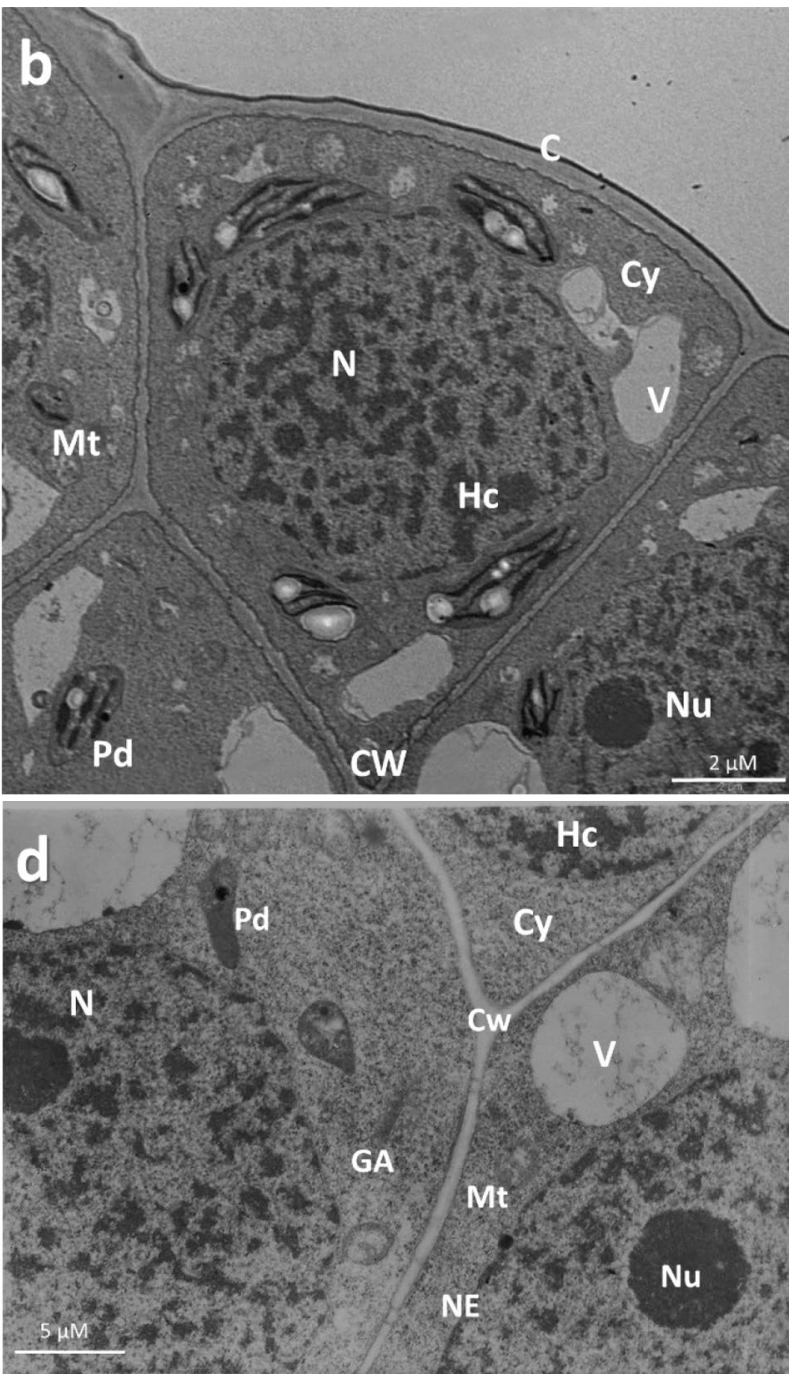

the dominant nuclei with patches of heterochromatin throughout the nuclear interior, an active cytoplasm with abundant organelles, and the presence of multiple vacuolar structures. $C W$ cell wall, $C y$ cytoplasm, $H c$ heterochromatin, $C$ cuticle, $G A$ Golgi apparatus, $L$ leaf, L1, L2 tunica, $L 3$ corpus, $M t$ mitochondria, $N$ nucleus, $N E$ nuclear envelope, $N u$ nucleolus, $P$ primordium, $P d$ plastid, $V$ vacuole (a semi-thin section, TB-stained; b-d transmission electron micrographs)

results refer to real numerical data, while alphabet letters point to homogenous groups based on transformed data.

\section{Results}

\section{Effect of cryopreservation on the shoot tip survival and their morphogenetic reactions}

After 7 days of post-thaw culture, surviving cryopreserved shoot tips showed green colour (Fig. 1a), while dead ones became dark brown. The post-rewarming shoot tip

Statistica 10.0 and ANALWAR-5.2-FR tools. Tables with 


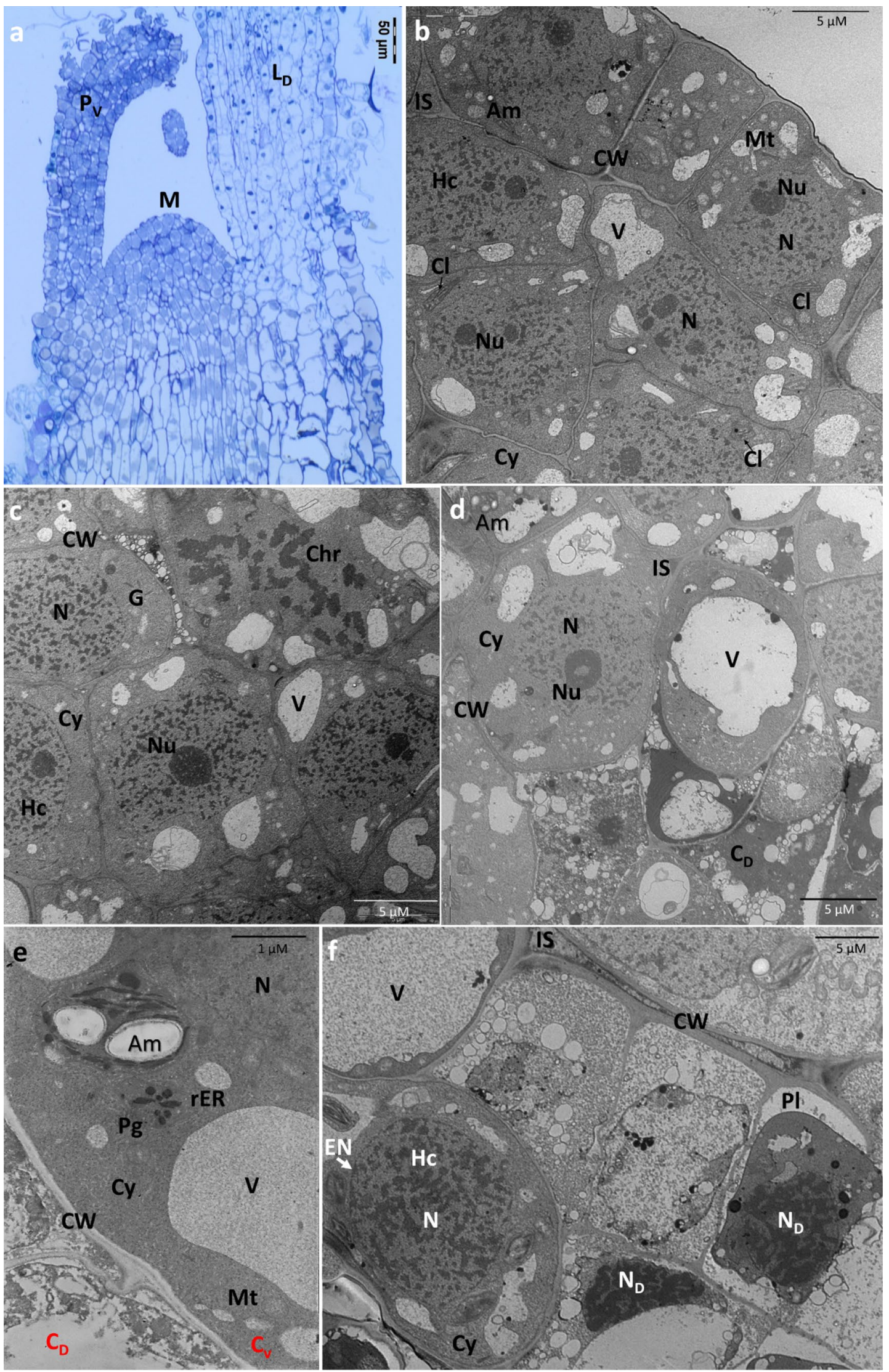


४Fig. 4 First type of damage of cryopreserved 'Lady Orange' shoot tips. a longitudinal section of shoot tip with a viable meristem and leaf primordium; 2 days after rewarming, b viable tunica cells (L1 and L2 layers) which fully regained their original level of vacuolisation and are structurally similar to the control, c metabolically active and dividing corpus cells, $\mathbf{d}$ viable (upper part) and degenerating (lower part) cells from the deeper layers of the corpus, e ultrastructure of a viable cell with typical organelles, adjacent to a dead cell, $\mathbf{f}$ corpus cells with signs of degradation (nuclei disintegration, cell plasmolysis). $A m$ amyloplast, $C_{D}$ cell dead, $C_{V}$ cell viable, $C h r$ chromosome, $\mathrm{Cl}$ chloroplast, $\mathrm{CW}$ cell wall, $C y$ cytoplasm, $G$ Golgi apparatus, $H c$ heterochromatin, $I S$ intercellular spaces, $L_{D}$ leaf dead, $M$ meristem, $M t$ mitochondria, $N$ nucleus, $N_{D}$ degraded nucleus, $N E$ nuclear envelope, $\mathrm{Nu}$ nucleolus, $P g$ plastoglobule, $P l$ plasmolysis, $P_{V}$ primordium viable, $r E R$ rough endoplasmic reticulum, $V$ vacuole (a semi-thin section, TB-stained; b-e transmission electron micrographs)

survival ranged from 42.5 to $66.7 \%$ (Tab. 1). Seven days after rewarming, the growth of cryopreserved shoot tips began from the development of the leaf covering the meristem. The alginate bead did not stop the development of shoots (Fig. 1b). Even several leaves could develop inside it (Fig. 1c). The first (Fig. 1b) or successive (Fig. 1d) leaves easily broke the bead. The further growth of the shoot took place on the surface of the capsule (Fig. 1b, d).

Plant regrowth from non-treated control shoot tips was $100 \%$, and no shoot deformation, callus formation or a multiple-shoot recovery was noticed (Tab. 1; Fig. 2a). In a screen of three Chrysanthemum $\times$ grandiflorum cultivars $48-81 \%$ of rewarmed viable shoot tips developed typical single shoots (Fig. 2b). The remaining explants produced the multiple shoots (Fig. 2c, d). Two paths in multiple structure recovery were distinguished. In the first group were those, which grew in a number of two or three from a single explant and showed no malformation (Fig. 2c). Others $(3.7-10.3 \%)$ regenerated through a brown, glossy callus, and they were usually deformed (Fig. 2d). Those structures had short internodes, fasciated leaves and were unable to further development.

All cryopreservation-derived shoots grew slower than the control plantlets (especially 'Lady Orange' chrysanthemums). The development of multiple shoots was the slowest. About $42-75 \%$ of recovered shoots were able to spontaneous root formation (Fig. 2c; Table 1). The control shoots regenerated roots during the first month of culture, while the shoots recovered after cryopreservation were not able to do it until the second month of post-thaw culture. None of the malformed shoots were capable of rooting.

\section{Histological and ultrastructural characterisation of shoot tips recovered after cryopreservation}

'Lady Orange' and 'Lady Salmon' explants were subjected to microscopic analysis; however, due to a similar trend of structural changes observed in both cultivars, only photographical documentation of 'Lady Orange' is presented in the paper.

In the control shoot tips, dense cytoplasm was observed in the cells of leaf primordia and the apical dome (Fig. 3a). The cells of the L1 layer were cylindrical and tightly arranged (Fig. 3b). Their outer cell wall was covered with cuticle. The nuclei, unlike smaller numerous vacuoles, were centrally located and abundant in condensed heterochromatin. The L2 layer cells were more vacuolated, although still they had prominent nuclei with even two nucleoli (Fig. 3c). As for the corpus and leaf primordia, the cells were more elongated (Fig. 3d). They had large nuclei and cytoplasm rich with plastids and mitochondria.

The microscopic analysis revealed three types of structural damages in shoot tips after their cryopreservation. In the first of them, the shoot tips had fully viable meristem (both tunica layers and the corpus), as well as one or two primordia and entirely or partially viable leaf with dividing cells (Fig. 4a). All of those organs had a typical cell organisation. Similar to the control, the cells of the L1 tunica layer were cylindrical, small and closely arranged (Fig. 4b). Their nuclei were prominent, well shaped and centrally located having one or two nucleoli. The vacuoles were smaller, numerous and peripherally located. Numerous mitochondria were also present in those cells. The L2 layer cells were more vacuolated, although still they had pronounced nuclei (Fig. 4b). As for the corpus cells, the vacuoles occupied the greatest space, while the nuclei were smaller (Fig. 4c). Some of the meristematic cells were already dividing at day 2 of post-thaw culture. Extensive necrosis or cell abnormalities, e.g., shrunk protoplasts, disintegrated plasmalemma, were visible only in the deeper parenchymatic parts of the explants (Fig. 4d-f).

In the second type of structural damages, the meristem did not survive LN storage (partially or entirely); however, one or two leaf primordia were fully viable (Fig. 5a). The meristematic cells had shrunk protoplasts and damaged organelles (Fig. 5b). Cell disturbances were present in both the tunica and corpus parts. In those explants, the cells localised in the leaf axil were highly metabolically active with even two nucleoli present in a single nucleus (Fig. 5c). The ultrastructure of the viable explant parts was not altered in comparison with the control. Leaf cells were elongated, more vacuolated and their cytoplasm was rich in mitochondria and chloroplasts (Fig. 5d). Their cell walls were intact. As for those explants already 5 days after rewarming, a development of axillary shoots in the leaf axil was observed (Fig. 5e, f).

The third type of structural damages showed that there are shoot tips in which only the part of a young leaf survived LN storage (Fig. 6a). Viable cells were metabolically active and structurally similar to the control cells. They were able to undergo proliferation already after 2 days of recovery culture 

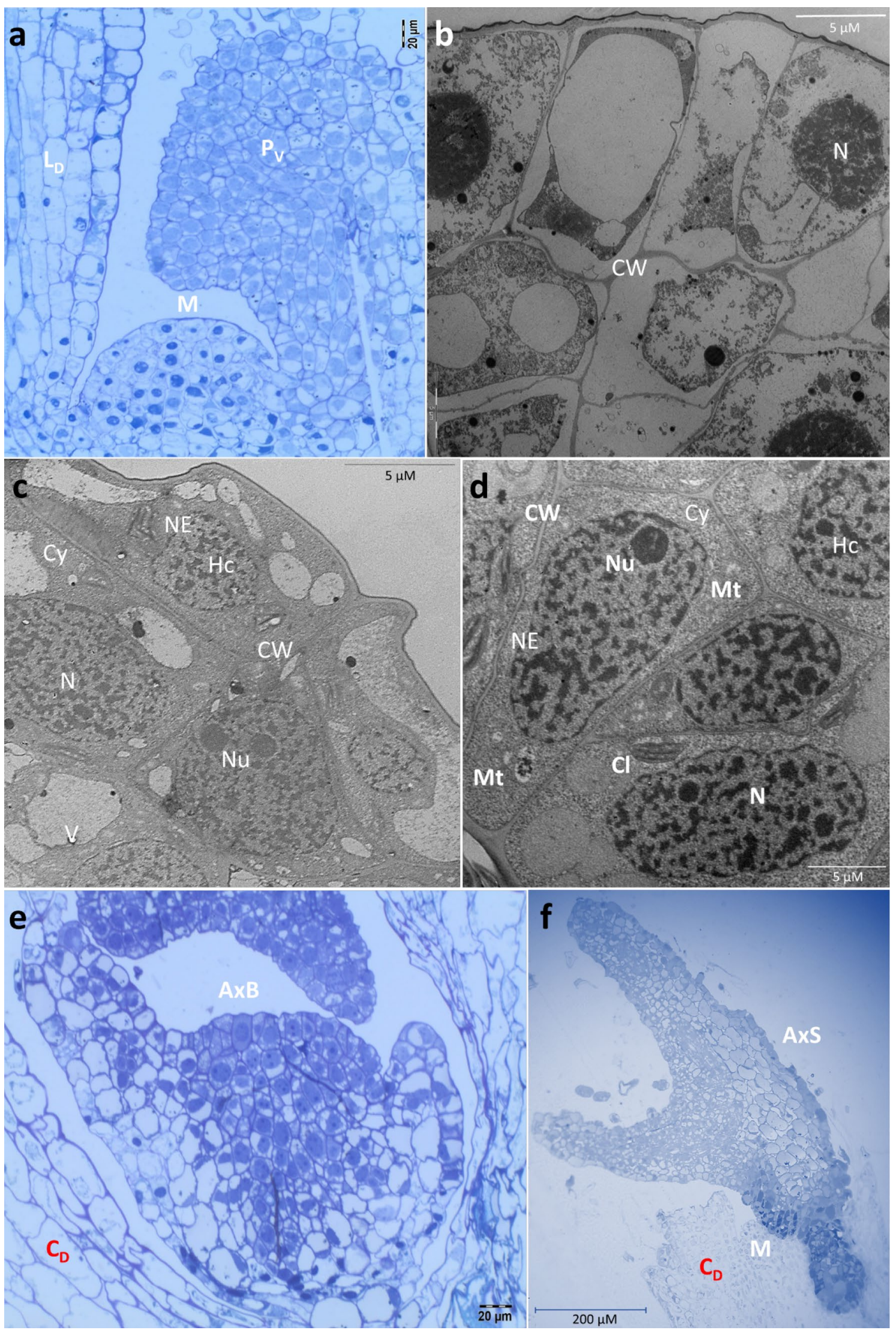
4Fig. 5 Second type of damage of 'Lady Orange' shoot tips after cryopreservation. a Shoot tip with a dead meristem and viable leaf primordium, b apical meristem with degraded cellular organelles, c viable leaf axil cells, $\mathbf{d}$ ultrastructure of fully viable leaf primordium cells of elongated shape with prominent nuclei, spherical mitochondria, e semi-thin section of a new formed axillary bud in the leaf axil, f semi-thin section of a developing axillary shoot (apical meristem and leaves are dead). $A x B$ axillary bud, $A x S$ axillary shoot, $C_{D}$ cells dead, $\mathrm{Cl}$ chloroplast, $\mathrm{CW}$ cell wall, $\mathrm{Cy}$ cytoplasm, $\mathrm{Hc}$ heterochromatin, $L_{D}$ leaf dead, $M$ meristem, $M t$ mitochondria, $N$ nucleus, $N E$ nuclear envelope, $N u$ nucleolus, $P_{V}$ primordium viable, $V$ vacuole (a, e, $\mathbf{f}$ semi-thin sections, TB-stained; b-d transmission electron micrographs; a-d 2 days after rewarming; $\mathbf{e}-\mathbf{f} 5$ days after rewarming)

(Figs. 6b, c). Those cells were divided many times within the next 3 days of culture (Fig. 6d). This was not observed among the leaves of control explants.

\section{Effect of cryopreservation on plantlet acclimatisation}

Both, the rooting (on the IAA-supplemented medium) and acclimatisation efficiency were $100 \%$ for the control and cryopreserved-derived plants of all studied cultivars (Table 2). In the end, 32 'Richmond', 36 'Lady Orange' and 22 'Lady Salmon' plants were recovered. No differences in the morphology or deformations within the cryopreservationderived and control plants were visually observed.

\section{Discussion}

\section{Cryopreservation efficiency}

One of the main problems associated with developing effective cryopreservation protocols is the necessity of their optimisation for different cultivars (Kulus and Zalewska 2014a). Moreover, the plant tolerance to exogenous factors can be even genotype-dependent. The differences in shoot tip survival between Chrysanthemum $\times$ grandiflorum cultivars studied here reached even $35 \%$. The influence of cultivar on the cryopreservation efficiency was also observed with pelargonium, gladiolus and chrysanthemum, in which the survival levels ranged between 9.1-70.6, 4.9-28.0 and 46.0-91.0\%, respectively (Gallard et al. 2008; Joung et al. 2007; Halmagyi et al. 2004). In contrast, with rose and carnation, the genetic factor remained insignificant (survival rates: 65 and 95\%, respectively) (Halmagyi and Pinker 2006; Sekizawa et al. 2011). Moreover, our studies clearly show that cryopreservation influences the morphogenetic response of shoot tips, and that their reaction in post-thaw culture is also dependent on genotype. In the present research the formation of single and multiple shoots was observed. The share of multiple shoots reached from $19.4 \%$ ('Richmond') to $51.8 \%$ ('Lady Salmon'). By comparison, Karimi et al.
(2002) obtained a multiple-shoots regeneration in $91 \%$ of non-cryopreserved chrysanthemum shoot tips on the MS medium with $0.09 \mathrm{M}$ sucrose and $4.44 \mu \mathrm{M}$ BA (probably due to the presence of cytokinin), while Wang et al. (2014) obtained $48 \%$ of multiple shoots regenerated via callus after cryopreservation of 'Japanese Red' chrysanthemum via the droplet-vitrification method. As for Gladiolus, shoots from two in vitro-grown cultivars were sensitive to KIN resulting in a high rate $(20-80 \%)$ of abnormal-looking regenerants (Joung et al. 2007). According to Agbidinoukoun et al. (2013), the callus induction mechanism is still poorly understood and depends mostly on genotype, which could explain the differences between cultivars observed in this study.

\section{Morphogenetic response of the explant after cryopreservation}

It was shown previously that cryopreservation treatments cause cell damage (Wesley-Smith et al. 2014). For example, with Dioscorea rotundata Poir typical plantlet development was obtained for $-70{ }^{\circ} \mathrm{C}$-cooled shoot tips, whereas only callus development occurred from tissues exposed to LN (Quain et al. 2009). Early scanning electron microscopy (SEM) analysis showed that only a small part of the chrysanthemum shoot tip survived classical cryopreservation, especially after applying dimethyl sulfoxide (DMSO) (Fukai and Oe 1990). Xu et al. (2006) observed that cryopreservation using vitrification technique often lead to numerous cell abnormalities in kiwi shoot tips, such as: smaller and more numerous vacuoles, denser cytoplasm, starch accumulation and larger cell lumen. Our research, however, confirmed the possibility of securing not only the entire meristem (both tunica and the deeper parts of the corpus) but also leaf primordia and even large parts of young leaf with no change in their structure. Similar to our results, Kartha (1985) reported that in Dianthus most of subapical tissue was damaged, while the meristem and leaf primordia remained viable. As a consequence, a fully protected shoot tip was capable of forming a single shoot in post-rewarming culture.

In the past it was very rarely observed that the cells which are larger and more differentiated than the meristematic ones can survive storage in LN. Histological observations performed by Wang et al. (2014) showed that only the three outer layers of chrysanthemum meristem cells remained viable after cryopreservation. However, in Cosmos atrosanguineus (Hook.) Voss and Lilium sp. it was shown that beside the meristem also the young parts of the primordium can survive freezing (Wilkinson et al. 2003; Yin et al. 2014). Our study revealed that even if the meristem of chrysanthemum 'Lady Orange' and 'Lady Salmon' did not survive storage in LN, other parts of the shoot tip, such as primordia and/or young leaf, were able to further development. As a result of meristem damage, recovery of multiple shoots from 


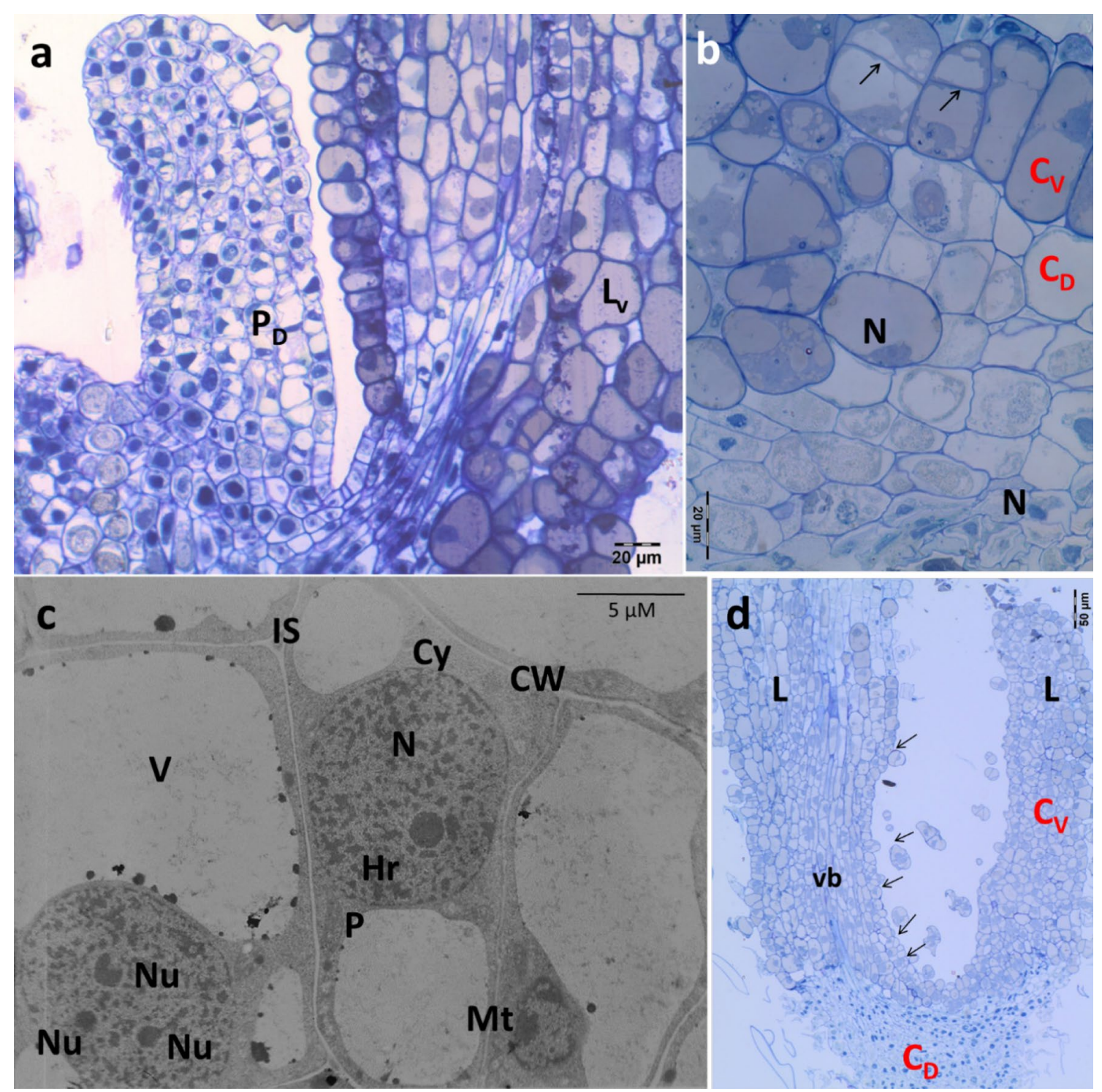

Fig. 6 Third type of damage of cryopreserved 'Lady Orange' shoot tips. a Longitudinal section through a shoot tip in which only a part of the young leaf survived LN storage, b living, proliferating, epidermal cells with viable cytoplasm and nuclei (indicated with arrows) and dead cells of the leaf mesophyll with shrunk protoplasm and malformed nuclei, $\mathbf{c}$ viable strongly vacuolated abaxial leaf cells with prominent active nuclei with even three nucleoli, $\mathbf{d}$ multiple dividing leaf epidermis cells (indicated with arrows). $C_{D}$ cells dead, $C_{V}$ cells viable, $C W$ cell wall, $C y$ cytoplasm, $H c$ heterochromatin, $L$ leaf, $L_{v}$ leaf viable, $M t$ mitochondria, $N$ nucleus, $N u$ nucleolus, $P$ plastid, $P_{D}$ primordium dead, $V$ vacuole, $v b$ vascular bundle. a-c Semi-thin sections, TB-stained; $\mathbf{d}$ transmission electron micrograph; a-c 2 days after rewarming, $\mathbf{d} 5$ days after rewarming
Table 2 Effect of

cryopreservation (LN) on the rooting and acclimatisation of the shoots recovered

\begin{tabular}{|c|c|c|c|c|c|c|}
\hline & \multicolumn{2}{|c|}{ 'Richmond' } & \multicolumn{2}{|c|}{ 'Lady Orange’ } & \multicolumn{2}{|c|}{ ‘Lady Salmon’ } \\
\hline & Control & $\mathrm{LN}$ & Control & $\mathrm{LN}$ & Control & $\mathrm{LN}$ \\
\hline Number of recovered plants & 10 & 32 & 15 & 36 & 10 & 22 \\
\hline Rooting efficiency [\%] & $100 \mathrm{a}$ & $100 \mathrm{a}$ & $100 \mathrm{a}$ & $100 \mathrm{a}$ & $100 \mathrm{a}$ & $100 \mathrm{a}$ \\
\hline Acclimatisation efficiency [\%] & $100 \mathrm{a}$ & $100 \mathrm{a}$ & $100 \mathrm{a}$ & $100 \mathrm{a}$ & $100 \mathrm{a}$ & $100 \mathrm{a}$ \\
\hline
\end{tabular}

Control refers to plants produced from non-precultured and non-cryotreated shoot tips

* Means marked with the same letter do not differ significantly at $P=0.05$ 
the viable part of apical meristem, leaf primordia, leaf axil or indirect regeneration through callus may occur. Similarly, histological studies revealed that shoots could be recovered from not-fully viable apple shoot-tips, if groups of cells in the leaf primordia and most of the cells in the apical dome survived storage in LN (Feng et al. 2013).

Our results suggest that due to apical dominance elimination, viable cells of the axillary meristem form directly typical axillary shoots (in a number of two or three from a single explant). Those shoots present no signs of malformation. However, if the entire meristem and leaf axil cells are dead, the proliferation of viable leaf cells may lead to the formation of callus tissue, and then regeneration of adventitious shoots. Similar results were observed with chrysanthemum 'Jinba', 'Lishui Yeju' (Liu et al. 2009), 'Japanese Red' and 'Xizi Qiuzhuang' (Wang et al. 2014). This phenomenon is undesired since it may lead to chimera component separation, as observed with chrysanthemum 'Apricot Marble' (Fukai et al., 1994). Furthermore, such plantlets have no commercial value due to excessive malformation. Fortunately, in the studied cultivars, those shoots were incapable of plantlet formation. One of the possible reasons of such malformation is mutation within the so-called house-keeping genes. The share of the malformed shoots can be minimised by the addition of gibberellic acid $\left(\mathrm{GA}_{3} ; 0.05 \mathrm{mg} \mathrm{dm}^{-3}\right)$ into the recovery medium (Wang et al. 2014).

The observed ranges of cryoinjury (i.e., 1. survival of the entire meristem dome; 2 . injury of the apical meristem followed by formation of axillary buds from a viable primordium/leaf axil, and 3. survival and division of only young leaf cells), correspond with the three types of morphogenetic response in recovery culture: the formation of single, direct and indirect multiple shoots (Table 1).

\section{Influence of cryopreservation on rooting and acclimatisation efficiency}

In the past little attention was paid to rooting and acclimatisation of the plantlets after cryopreservation. Ai et al. (2012) reported that the Rabdosia rubescens shoots produced after encapsulation-dehydration cryopreservation showed an increased rooting efficiency in comparison to the untreated control. Hao et al. (2002) on the other hand, did not observe any influence of storage in $\mathrm{LN}$ on citrus rhizogenesis efficiency. As it was reported by Kulus and Zalewska (2014b) encapsulation in Na-alginate inhibits the formation of both spontaneous and IAA-induced chrysanthemum roots. The negative influence of cryopreservation was observed in the present study; the control plants regenerated spontaneously roots within 30 days of culture, while those recovered from the cryopreserved shoot tips started to form roots 2 months after thawing. On the other hand, after dissecting the nonmalformed shoots from the capsules and placing them on the
IAA-supplemented medium, a 100\% rooting efficiency was obtained. Therefore, it can be assumed that the alginate bead represents the main limiting factor of spontaneous rooting.

In the present research no influence of cryopreservation on the plant acclimatisation efficiency was recorded. Similar results were observed in shoot tips-derived plantlets of Solanum lycopersicum L. (Coste et al. 2014). On the other hand, cryopreservation lead to a more than twofold lower acclimatisation efficiency of plantlets in Bactris gasipaes L. (Steinmacher et al. 2007).

\section{Conclusions}

Cryopreservation by encapsulation-dehydration affects the morphogenetic response of chrysanthemum shoot tips. It leads to malformation of some shoots and spontaneous rooting inhibition. In fully secured shoot tips, not only the meristem but also leaf primordia can survive storage in $\mathrm{LN}$. The elimination of apical dominance by cryoinjuries favours the formation of multiple shoots, including indirect organogenesis. For plants that are periclinal chimeras, such as chrysanthemum 'Lady Orange' and 'Lady Salmon', this regeneration path can lead to the loss of ornamental properties. Therefore, the further research will be conducted to explain whether the described cryopreservation procedure affects the stability of the tested cultivars. An efficient chrysanthemum cryopreservation protocol will grant an easy and cost-efficient access of future generations of breeders and producers to genetic resources of high quality and diversity range, which are essential in the creation of new cultivars of this economically important genus.

Author contributions statement DK-designed and performed the experiments; DK, AA, AM-performed TEM analysis; DK and AM-wrote the manuscript.

Acknowledgements This study was funded by the Polish Ministry of Science and Higher Education ("Iuventus Plus", Grant No. IP2014023373).

\section{Compliance with ethical standards}

Conflict of interest The authors declare that they have no conflict of interest.

Open Access This article is distributed under the terms of the Creative Commons Attribution 4.0 International License (http://creativecomm ons.org/licenses/by/4.0/), which permits unrestricted use, distribution, and reproduction in any medium, provided you give appropriate credit to the original author(s) and the source, provide a link to the Creative Commons license, and indicate if changes were made. 


\section{References}

Agbidinoukoun A, Ahanhanzo C, Adoukonou-Sagbadja H, Adjassa M, Djikpo-Tchibozo MA, Agbangla C (2013) Impact of osmotic dehydration on the encapsulated apices survival of two yams (Dioscorea spp.) genotypes from Benin. J App Biosci 65:49995007. https://doi.org/10.4314/jab.v65i0.89642

Ai PF, Lu LP, Song JJ (2012) Cryopreservation of in vitro-grown shoot-tips of Rabdosia rubescens by encapsulation-dehydration and evaluation of their genetic stability. Plant Cell Tiss Org Cult 108:381-387. https://doi.org/10.1007/s11240-011-0049-x

Bush SR, Earle ED, Langhans RW (1976) Plantlets from petal segments, petal epidermis and shoot tips of the periclinal chimera Chrysanthemum morifolium 'Indianapolis'. Am J Bot 63:729-737

Coste A, Vălimăreanu S, Halmagyi A (2014) Cryopreservation and acclimatization of Lycopersicon esculentum (Mill.) genotypes. Notulae Botanicae Horti Agrobotanici Cluj-Napoca 42(2):466471. https://doi.org/10.15835/nbha.42.2.9579

Engelmann F (2011) Use of biotechnologies for the conservation of plant biodiversity. In Vitro Cell Dev Biol Plant 47:5-16. https:// doi.org/10.1007/s11627-010-9327-2

Feng C-H, Cui Z-H, Li B-Q, Chen L, Ma Y-L, Zhao Y-H, Wang Q-C (2013) Duration of sucrose preculture is critical for shoot regrowth of in vitro-grown apple shoot-tips cryopreserved by encapsulation-dehydration. Plant Cell Tiss Org Cult 112(3):369-378. http s://doi.org/10.1007/s11240-012-0245-3

Fukai S, Oe M (1990) Morphological observations of chrysanthemum shoot tips cultured after cryoprotection and freezing. J Jpn Soc Hortic Sci 59(2):383-387. https://doi.org/10.2503/jjshs.59.383

Fukai S, Goi M, Tanaka M (1994) The chimeric structure of the apical dome of chrysanthemum (Dendranthema grandiflorum (Ramat.) Kitam.) is affected by cryopreservation. Sci Hortic 57:347-351. https://doi.org/10.1016/0304-4238(94)90117-1

Gallard A, Panis B, Dorion N, Swennen R, Grapin A (2008) Cryopreservation of Pelargonium apices by droplet-vitrification. CryoLett. 29(3):243-251

Halmagyi A, Pinker I (2006) Plant regeneration from Rosa shoot tips cryopreserved by a combined droplet vitrification method. Plant Cell Tiss Org Cult 84:145-153. https://doi.org/10.1007/s112 40-005-9012-z

Halmagyi A, Fischer-Kluver G, Mix-Wagner G, Schumacher HM (2004) Cryopreservation of Chrysanthemum morifolium (Dendranthema grandiflora Ramat.) using different approaches. Plant Cell Rep 22:371-375. https://doi.org/10.1007/s00299-003-0703-9

Halmagyi A, Coste A, Tripon S, Crăciun C (2017) Low temperature induced ultrastructural alterations in tomato (Lycopersicon esculentum Mill.) shoot apex cells. Sci Hortic 222:22-31. https://doi. org/10.1016/j.scienta.2017.04.019

Hao YJ, You CX, Deng XX (2002) Effects of cryopreservation on developmental competency, cytological and molecular stability of citrus callus. CryoLett. 23(1):27-35

Helliot B, Swennen R, Poumay Y, Frison E, Lepoivre P, Panis B (2003) Ultrastructural changes associated with cryopreservation of banana (Musa spp.) highly proliferating meristems. Plant Cell Rep 21:690-698

Hunter EE (1993) Practical electron microscopy—a beginner's Illustrated Guide, 2nd edn. Cambridge University Press, Cambridge, pp 372-373. https://doi.org/10.1093/ajcp/103.3.372a

Joung HY, Cantor M, Kamo K (2007) Cryopreservation of Gladiolus cultivars. Acta Hortic 760:225-231. https://doi.org/10.17660/Acta Hortic.2007.760.29

Karimi MZ, Amin MN, Azad MAK, Begum F, Islam MM, Alam R (2002) Effect of different plant growth regulators on in vitro shoot multiplication of Chrysanthemum morifolium. OnLine J Biol Sc 3(6):553-560. https://doi.org/10.3923/jbs.2003.553.560
Kartha KK (1985) Meristem culture and germplasm preservation. In: Kartha KK (ed) Cryopreservation of plant cells and organs. CRC Press, Boca Raton, pp 116-134. https://doi.org/10.1002/04712505 70.spi055

Kereša S, Mihovilović A, Barić M, Židovec V, Skelin M (2012) The micropropagation of chrysanthemums via axillary shoot proliferation and highly efficient plant regeneration by somatic embryogenesis. Afr J Biotechnol 11(22):6027-6033. https://doi.org/10.5897 /AJB10.1976

Kulus D (2015) Application of cryopreservation for chrysanthemum genetic resources conservation. Acta Hortic 1087:225-232. http s://doi.org/10.17660/ActaHortic.2015.1087.27

Kulus D, Zalewska M (2014a) Cryopreservation as a tool used in long-term storage of ornamental species-a review. Sci Hortic 168:88-107. https://doi.org/10.1016/j.scienta.2014.01.014

Kulus D, Zalewska M (2014b) In vitro plant recovery from alginate encapsulated Chrysanthemum $\times$ grandiflorum/Ramat./Kitam. shoot tips. Prop Ornam Plants 14(1):3-12

Kushnarenko S, Kovalchuk I, Mukhitdinova Z, Rakhimova E, Reed BM (2010) Ultrastructure study of apple meristem cells during cryopreservation. Asian Australas J Plant Sci Biotechnol 4(1):10-20

Liu YX, Liu ZC, Lin T, Li TF, Cheng FD, Lee I, Luo LJ (2009) Study on cryopreservation of shoot-tips of chrysanthemum through vitrification. J Plant Genet Resour 10(2):249-254

Martín C, Cervera MT, González-Benito ME (2011) Genetic stability analysis of chrysanthemum (Chrysanthemum $\times$ morifolium Ramat) after different stages of an encapsulation-dehydration cryopreservation protocol. J Plant Physiol 168:158-166. https:// doi.org/10.1016/j.jplph.2010.06.025

Miao N-H, Kaneko Y, Sugawara Y (2005) Ultrastructural implications of pretreatment for successful cryopreservation of Oncidium protocorm-like body. CryoLett 26(5):333-340

Mikuła A, Tykarska T, Kuraś M (2005) Ultrastructure of Gentiana tibetica proembryogenic cells before and after cooling treatments. CryoLett 26(6):367-378

Murashige T, Skoog F (1962) A revised medium for rapid growth and bio assays with tobacco tissue cultures. Physiol Plant 15:473-497. https://doi.org/10.1111/j.1399-3054.1962.tb08052.x

Poobathy R, Sinniah UR, Rathinam X, Subramaniam S (2013) Histology and scanning electron microscopy observations of cryopreserved protocorm-like bodies of Dendrobium sonia-28. Turk J Biol 37:1206-1222. https://doi.org/10.3906/biy-1206-22

Quain MD, Berjak P, Acheampong E, Kioko JI (2009) Sucrose treatment and explant water content: critical factors to consider in development of successful cryopreservation protocols for shoot tip explants of the tropical species Dioscorea rotundata (YAM). CryoLett 30(3):212-223

Reynolds ES (1963) The use of lead citrate at high pH as an electronopaque stain in electron microscopy. J Cell Biol 17:208-212. http s://doi.org/10.1083/jcb.17.1.208

Sekizawa K, Yamamoto S, Rafique T, Fukui K, Niino T (2011) Cryopreservation of in vitro-grown shoot tips of carnation (Dianthus caryophyllus $\mathrm{L}$.) by vitrification method using aluminium cryoplates. Plant Biotech 28:401-405. https://doi.org/10.5511/plantbio technology.11.0531a

Skyba M, Petijová L, Košuth J, Koleva DP, Ganeva TG, KapchinaToteva VM, Cellárová E (2012) Oxidative stress and antioxidant response in Hypericum perforatum L. plants subjected to low temperature treatment. J Plant Physiol 169(10):955-964. https://doi. org/10.1016/j.jplph.2012.02.017

Steinmacher AD, Saldanha CW, Clement CR, Guerra MP (2007) Cryopreservation of peach palm zygotic embryos. CryoLett 28(1):13-22

Stewart RN, Meyer FG, Dermen H (1972) Camellia + 'Daisy Eagleso' a graft chimera of Camellia sasanqua and C. japonica. Am J Bot 59(5):515-524 
Stoyanova-Koleva D, Stefanova M, Čellárová E, Kapchina-Toteva V (2013) Chloroplast ultrastructure of Hypericum perforatum plants regenerated in vitro after cryopreservation. Biol Plant 57(4):793796. https://doi.org/10.1007/s10535-013-0357-6

Stoyanova-Koleva D, Stefanova M, Ganeva TS, Čellárová E (2015) Structural modifications in the mesophyll associated with cryopreservation of seven Hypericum species. Biol Plant 59(3):514 520. https://doi.org/10.1007/s10535-015-0528-8

Szymkowiak EJ, Sussex IM (1996) What chimeras can tell us about plant development. Annu Rev Plant Physiol Mol Biol 47:351-376. https://doi.org/10.1146/annurev.arplant.47.1.351

Teixeira da Silva JA, Kulus D (2013) Chrysanthemum biotechnology: discoveries from recent literature. Folia Hortic 25(2):133-140. https://doi.org/10.2478/fhort-2014-0007

Wang R-R, Gao X-X, Chen L, Huo L-Q, Li M-F, Wang Q-C (2014) Shoot recovery and genetic integrity of Chrysanthemum morifolium shoot tips following cryopreservation by droplet-vitrification. Sci Hortic 176:330-339. https://doi.org/10.1016/j.scienta.2014 .07 .031

Wesley-Smith J, Berjak P, Pammenter NW, Walters C (2014) Intracellular ice and cell survival in cryo-exposed embryonic axes of recalcitrant seeds of Acer saccharinum: an ultrastructural study of factors affecting cell and ice structures. Ann Bot 113(4):695-709. https://doi.org/10.1093/aob/mct284

Wilkinson T, Wetten A, Prychid C, Fay MF (2003) Suitability of cryopreservation for the long-term storage of rare and endangered plant species: a case history of Cosmos atrosanguineus. Ann Bot 91:65-74. https://doi.org/10.1093/aob/mcg009

Xu X-B, Cai Z-G, Gu Q-G, Zhang Q-M (2006) Cell ultrastructure of kiwifruit (Actinidia chinensis) shoot tips during cryopreservation. Agric Sci China 5(8):587-590. https://doi.org/10.1016/S167 1-2927(06)60096-5

Yamaguchi H, Shimizu A, Hase Y, Degi K, Tanaka A, Morishita T (2009) Mutation induction with ion beam irradiation of lateral buds of chrysanthemum and analysis of chimeric structure of induced mutants. Euphytica 165:97-103. https://doi.org/10.1007 /s10681-008-9767-5

Yin Z-F, Bi W-L, Chen L, Zhao B, Volk GM (2014) An efficient, widely applicable cryopreservation of Lilium shoot tips by droplet vitrification. Acta Physiol Plant 36:1683-1692. https://doi. org/10.1007/s11738-014-1543-7

Zalewska M, Lema-Rumińska J, Miler N (2007) In vitro propagation using adventitious buds technique as a source of new variability in chrysanthemum. Sci Hortic 113:70-73. https://doi.org/10.1016 /j.scienta.2007.01.019

Zonneveld BJM (2007) Nuclear DNA content of ploidy chimeras of Hosta Tratt. (Hostaceae) demonstrate three apical layers in all organs, but not in the adventitious root. Plant Syst Evol 269:2938. https://doi.org/10.1007/s00606-007-0584-4

Zonneveld BJM, Van Iren F (2000) Flow cytometric analysis of DNA content in Hosta reveals ploidy chimeras. Euphytica 111:105-110. https://doi.org/10.1023/A:1003879408413 